\title{
Crystal Structure of Bis( $\mu$-hydroxo)diiron(III) Complex with Tripodal Ligands Having a Terminal Carboxylate Group
}

\author{
Xi Zhang, ${ }^{*}$ Hideki Furutachi, ${ }^{* \dagger}$ Yuya Ohyama, ${ }^{*}$ Shuhei Fujinami, ${ }^{*}$ Shigehisa Akine,*,** and \\ Masatatsu SUZUKI*
}

*Department of Chemistry, Division of Material Sciences, Graduate School of Natural Science and Technology, Kanazawa University, Kakuma-machi, Kanazawa 920-1192, Japan

**Nano Life Science Institute (WPI-NanoLSI), Kanazawa University, Kakuma-machi, Kanazawa 920-1192, Japan

\begin{abstract}
The structure of the dinuclear Fe(III) complex $\left[\mathrm{Fe}_{2}\left(6 \mathrm{Me}_{2}-\mathrm{BPP}\right)_{2}(\mathrm{OH})_{2}\right]\left(\mathrm{NO}_{3}\right)_{1.9553} \cdot \mathrm{Br}_{0.0447} \cdot 8 \mathrm{H}_{2} \mathrm{O}$ (1) was determined by $\mathrm{X}$-ray crystallography, where $6 \mathrm{Me}_{2}-\mathrm{BPP}$ is $\mathrm{N}, \mathrm{N}$-bis(6-methyl-2-pyridylmethyl)-3-aminopropionate. The compound crystallizes in a triclinic space group, $P \overline{1}$, with $a=10.3845(15), b=11.1976(15), c=20.389(4) \AA, \alpha=82.119(10)$, $\beta=85.340(10), \gamma=68.871(7)^{\circ}, Z=2, V=2189.3(6) \AA^{3}$. The $R 1[I>2 \sigma(I)]$ and $w R 2$ (all data) values are 0.0342 and 0.0972 , respectively, for all 9586 independent reflections. The complex has a bis( $\mu$-hydroxo)diiron core structure.
\end{abstract}

(Received November 16, 2018; Accepted December 17, 2018; Published on web April 10, 2019)

Hydroxo- or oxo-bridged non-heme diiron centers with terminal carboxylates are structural motifs found in metalloproteins, such as soluble methane monooxygenase (sMMO) and ribonucleotide reductase (RNR). ${ }^{1-4}$ Synthetic diiron model complexes with $\mathrm{Fe}_{2}(\mathrm{OH})_{2}, \mathrm{Fe}_{2}(\mathrm{O})(\mathrm{OH})$, and $\mathrm{Fe}_{2}(\mathrm{O})_{2}$ cores are of particular importance for obtaining fundamental insights into the structural and spectroscopic properties of the active centers in the metalloproteins mentioned above. ${ }^{2-4}$ Previously, we reported that the crystal structure of a $(\mu$-oxo $)(\mu$-hydroxo $)$ diiron(III) complex, $\left[\mathrm{Fe}_{2}\left(6 \mathrm{Me}_{2}-\mathrm{BPP}\right)_{2}(\mathrm{O})(\mathrm{OH})\right]^{+}(2),{ }^{5}$ with a tetradentate tripodal ligand $\left(6 \mathrm{Me}_{2}-\mathrm{BPP}\right)$ having a terminal carboxylate, which was derived from deprotonation of its conjugate acid, $\left[\mathrm{Fe}_{2}\left(6 \mathrm{Me}_{2}-\mathrm{BPP}\right)_{2}(\mathrm{OH})_{2}\right]^{2+}$. In this paper, we report on the crystal structure of the bis $\left(\mu\right.$-hydroxo)diiron(III) complex $\left[\mathrm{Fe}_{2}\left(6 \mathrm{Me}_{2}-\right.\right.$ BPP $\left.)_{2}(\mathrm{OH})_{2}\right]\left(\mathrm{NO}_{3}\right)_{1.9553} \cdot \mathrm{Br}_{0.0447} \cdot 8 \mathrm{H}_{2} \mathrm{O}$ (1) (Fig. 1).

A single crystal of $\left[\mathrm{Fe}_{2}\left(6 \mathrm{Me}_{2}-\mathrm{BPP}\right)_{2}(\mathrm{OH})_{2}\right]\left(\mathrm{NO}_{3}\right)_{1.9553} \cdot \mathrm{Br}_{0.0447} \cdot$ $8 \mathrm{H}_{2} \mathrm{O}$ (1) suitable for X-ray crystallography was obtained by the recrystallization of $\left[\mathrm{Fe}_{2}\left(6 \mathrm{Me}_{2}-\mathrm{BPP}\right)_{2}(\mathrm{OH})_{2}\right]\left(\mathrm{NO}_{3}\right)_{2} \cdot 4.5 \mathrm{H}_{2} \mathrm{O}^{5}$ from water. It was picked up on a hand-made cold copper plate mounted inside a liquid $\mathrm{N}_{2}$ Dewar vessel and mounted on a glass rod at $-80^{\circ} \mathrm{C}$. X-ray diffraction measurements were made on a Rigaku CCD Mercury diffractometer with graphite monochromated Mo $K \alpha$ radiation at $123 \mathrm{~K}$. The structure was solved by a direct method (SHELXS 97) ${ }^{6}$ and expanded using a Fourier technique. The structure was refined by a full-matrix least-squares method by using the SHELXL $2014^{7}$ (Yadokari$\mathrm{XG)}{ }^{8}$ The asymmetric unit contains two very similar molecules that could be nearly related by each other with a translation symmetry in the $\left[\begin{array}{lll}0 & 1 & 1\end{array}\right]$ direction. This could be interpreted as a structure with a half unit-cell volume. However, the counter anions $\left(\mathrm{NO}_{3}{ }^{-}, \mathrm{Br}^{-}\right)$and crystallizing water molecules are located at different positions that could not be related by a translational symmetry. Also, the diffractions with $k+l=$ odd showed significant intensities (around $1 / 3$ of those with $k+l=$ even). Therefore, we concluded that the structure should have two

† To whom correspondence should be addressed.

E-mail: h-furutachi@se.kanazawa-u.ac.jp independent molecules in the asymmetric unit. All nonhydrogen atoms were refined with anisotropic displacement parameters. The hydrogen atoms in the $\mu$-hydroxo groups and water molecules were restrained to ensure reasonable distances ( $0.84 \AA$ ) by applying the default values for O-H DFIX restraints. Other hydrogen atoms were included using a riding model. The crystal data are summarized in Table 1.

$\mathrm{X}$-ray crystallography of $\mathbf{1}$ reveals that the asymmetric unit contains two halves of complex cations, $\left[\mathrm{Fe}_{2}\left(6 \mathrm{Me}_{2}-\mathrm{BPP}\right)_{2}(\mathrm{OH})_{2}\right]^{2+}$ (molecules A and B), 1.9553 nitrate ions, 0.0447 bromide ion, and eight water molecules. The partial content of the bromide ion appears to be due to the preparation route of the $6 \mathrm{Me}_{2-}$ BPPH ligand, which was obtained from the reaction of bis(6methyl-2-pyridylmethyl)amine with 3-bromopropionic acid in the presence of triethylamine. ${ }^{5}$

ORTEP drawing of the complex cation $\left[\mathrm{Fe}_{2}\left(6 \mathrm{Me}_{2}-\mathrm{BPP}\right)_{2-}\right.$ $\left.(\mathrm{OH})_{2}\right]^{2+}$ (molecule A) is shown in Fig. 2. Selected bond distances $(\AA)$ and angles $\left(^{\circ}\right)$ are given in Table 2 . Only the

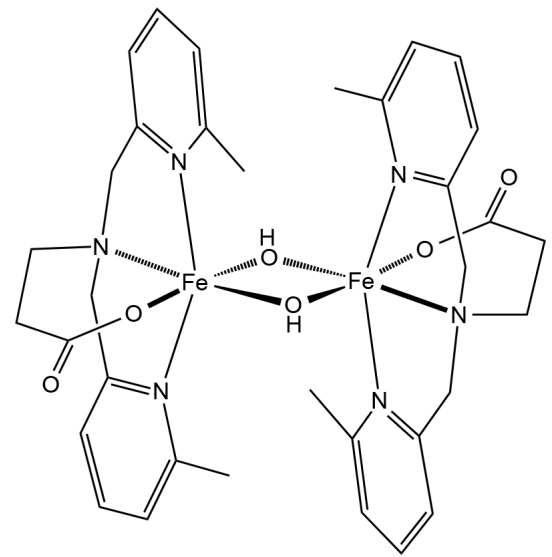

Fig. 1 Chemical diagram of the complex cation, $\left[\mathrm{Fe}_{2}\left(6 \mathrm{Me}_{2}-\right.\right.$ $\left.\mathrm{BPP})_{2}(\mathrm{OH})_{2}\right]^{2+}$ of $\mathbf{1}$ 
Table 1 Crystal and experimental data

Chemical formula: $\mathrm{C}_{34} \mathrm{H}_{58} \mathrm{Br}_{0.04} \mathrm{Fe}_{2} \mathrm{~N}_{7.96} \mathrm{O}_{19.87}$

Formula weight $=1011.38$

$T=123 \mathrm{~K}$

Crystal system: triclinic

$a=10.3845(15) \AA$

$b=11.1976(15) \AA$

$c=20.389(4) \AA$

$V=2189.3(6) \AA^{3}$

$D_{\mathrm{x}}=1.534 \mathrm{~g} / \mathrm{cm}^{3}$

Radiation: $\operatorname{Mo} K \alpha(\lambda=0.71073 \AA)$

$\mu($ Mo $K \alpha)=0.791 \mathrm{~cm}^{-1}$

$F\left(\begin{array}{lll}0 & 0 & 0\end{array}\right)=1060$

Crystal size $=0.40 \times 0.40 \times 0.20 \mathrm{~mm}^{3}$

No. of reflections collected $=23558$

No. of independent reflections $=9586$

$\theta$ range for data collection $=3.028$ to $27.483^{\circ}$

Data/Restraints/Parameters $=9586 / 82 / 661$

Goodness-of-fit on $F^{2}=1.091$

$R$ indices $[I>2 \sigma(I)]: R 1=0.0342, w R 2=0.0920$

$R$ indices (all data): $R 1=0.0481, w R 2=0.0972$

$(\Delta / \sigma)_{\max }=0.002$

$(\Delta \rho)_{\max }=0.321 \mathrm{e}^{-3}(\Delta \rho)_{\min }=-0.343 \mathrm{e}^{-3}$

Measurement: Rigaku CCD Mercury Diffractometer

Data collection \& cell refinement program: CrystalClear

Structure solving program: SHELXS 97

Structure determination: SHELXL 2014

Refinement: full-matrix least squares against $F^{2}$

CCDC deposition number: CCDC 1879204

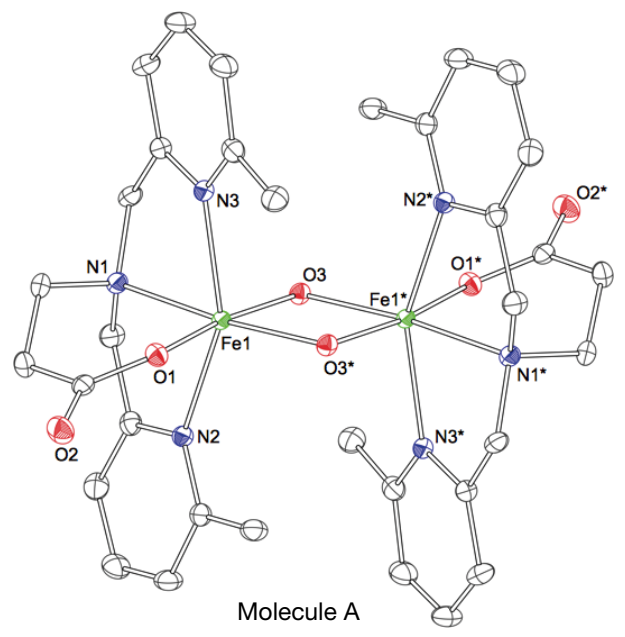

Fig. 2 ORTEP drawing of the complex cation, $\left[\mathrm{Fe}_{2}\left(6 \mathrm{Me}_{2}\right.\right.$ $\left.\mathrm{BPP})_{2}(\mathrm{OH})_{2}\right]^{2+}$ (molecule A) of $\mathbf{1}$, showing $50 \%$ probability ellipsoids. The hydrogen atoms are omitted for clarity.

molecular structure of molecule $\mathrm{A}$ is discussed here in detail, since the structural features of the two molecules are similar (Table 2 and Figs. 2 and 3). The diiron(III) center is doubly bridged by exogenous hydroxo groups to form a bis( $\mu$-hydroxo)diiron(III) core, as found for closely related bis( $\mu$-hydroxo)diiron(III) complexes with bidentate, ${ }^{9,10}$ tridentate, ${ }^{11}$ and tetradentate ligands. ${ }^{12-14}$ Each iron has an octahedral structure with an $\mathrm{N}_{3} \mathrm{O}_{3}$ donor set, where three nitrogen atoms of $6 \mathrm{Me}_{2-}$ $\mathrm{BPP}$ are in a mer-arrangement. The $\mathrm{Fe}-\mathrm{OH}$ bond trans to the carboxylate oxygen (Fe1-O3: 1.9867(10) $\mathrm{A})$ is slightly longer than the corresponding bond trans to the amino nitrogen ( $\mathrm{Fe} 1-$ O3*: $1.9400(11) \AA$ ) owing to the trans effect of the stronger
Table 2 Selected bond distances $(\AA)$ and angles $\left({ }^{\circ}\right)$

\begin{tabular}{lclc}
\hline \multicolumn{2}{c}{ Molecule A } & \multicolumn{2}{c}{ Molecule B } \\
\hline Fe1-O1 & $1.9271(10)$ & Fe2-O4 & $1.9352(10)$ \\
Fe1-O3 & $1.9867(10)$ & Fe2-O6 & $1.9800(10)$ \\
Fe1-O3*a & $1.9400(11)$ & Fe2-O6*b & $1.9417(11)$ \\
Fe1-N1 & $2.1591(12)$ & Fe2-N4 & $2.1575(13)$ \\
Fe1-N2 & $2.2410(12)$ & Fe2-N5 & $2.2309(13)$ \\
Fe1-N3 & $2.1945(12)$ & Fe2-N6 & $2.2016(13)$ \\
Fe1‥Fe1*a & $3.0886(6)$ & Fe2-.Fe2*b & $3.0869(6)$ \\
& & & \\
Fe1-O3-Fe1*a & $103.72(5)$ & Fe2-O6-Fe2*b & $103.84(5)$ \\
O3-Fe1-O3*a & $76.28(5)$ & O6-Fe2-O6*b & $76.17(5)$ \\
\hline
\end{tabular}

a. Symmetry operation: $-x+1,-y,-z+1$.

b. Symmetry operation: $-x+1,-y+1,-z$.

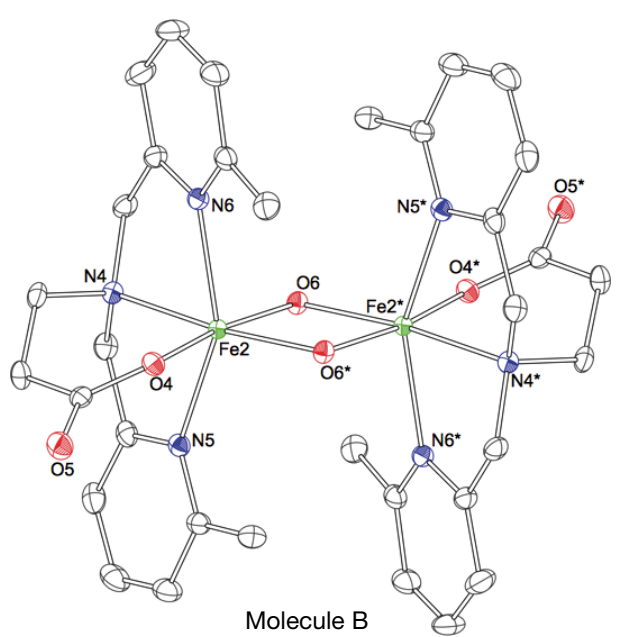

Fig. 3 ORTEP drawing of the complex cation, $\left[\mathrm{Fe}_{2}\left(6 \mathrm{Me}_{2-}\right.\right.$ BPP $\left.)_{2}(\mathrm{OH})_{2}\right]^{2+}$ (molecule B) of $\mathbf{1}$, showing $50 \%$ probability ellipsoids. The hydrogen atoms are omitted for clarity.

electron-donor ability of the carboxylate oxygen (Fe1-O1: $1.9271(10) \AA$ ), giving rise to a slightly asymmetric diamond core $(\Delta r=0.05 \AA)$. A similar deformation of the diamond core was made for bis $(\mu$-hydroxo)diiron(III) complexes with tridentate $(\Delta r=0.05-0.06 \AA)^{11}$ and tetradentate ligands $(\Delta r=0.03$ $0.09 \AA),{ }^{12-14}$ except for the complexes with bidentate ligands $(\Delta r=\sim 0.01 \AA) .{ }^{9,10}$ The Fe...Fe separation is 3.0886(6) $\AA$, which is on the short side of the range reported for related $\operatorname{bis}(\mu$ hydroxo)diiron(III) complexes $(3.008-3.172 \AA),{ }^{9-14}$ which is probably due to the stacking between the pyridine rings in $\mathbf{1}$ $(\sim 3.6 \AA)$. The $\mathrm{Fe}-\mathrm{OH}$ bond distances as well as the $\mathrm{Fe}-\mathrm{OH}-\mathrm{Fe}$ angle are in the range of those observed for related $\operatorname{bis}(\mu$ hydroxo)diiron(III) complexes. ${ }^{9-14}$ The Fe-ligand bond distances for $\mathbf{1}$ are characteristic of high-spin $\mathrm{Fe}(\mathrm{III})$ complexes, ${ }^{3,4}$ which are consistent with the Mössbauer spectrum of $\mathbf{1}\left(\delta\left(\Delta E_{\mathrm{Q}}\right)=0.42\right.$ (1.16) $\mathrm{mm} / \mathrm{s}) .^{5}$

The structural feature of $\mathbf{1}$ is quite similar to that of its conjugate base, $\left[\mathrm{Fe}_{2}\left(6 \mathrm{Me}_{2}-\mathrm{BPP}\right)_{2}(\mathrm{O})(\mathrm{OH})\right]^{+}(2)$, but protonation of 2 to 1 results in opening the $\mathrm{Fe}-\mathrm{O}(\mathrm{H})-\mathrm{Fe}$ angle from 100.2(1) to $103.72(5)^{\circ}$ and lengthening the $\mathrm{Fe}$... Fe distance from 2.969(1) to 3.0886(6) $\AA$. The Fe-O (carboxylate) and $\mathrm{Fe}-\mathrm{N}$ (amine) bonds trans to the hydroxo/oxo oxygens and the $\Delta E_{\mathrm{Q}}$ values are also affected by protonation. The $\mathrm{Fe}-\mathrm{O}$ (carboxylate) and $\mathrm{Fe}-\mathrm{N}$ (amine) bonds in 2 (1.979(3) and 2.175(3) A) become shorter in 1 (1.9271(10) and 2.1591(12) $\AA$ ). The $\Delta E_{\mathrm{Q}}$ value for 1 
$(1.16 \mathrm{~mm} / \mathrm{s})$ is smaller than that of $2\left(\Delta E_{\mathrm{Q}}=1.56 \mathrm{~mm} / \mathrm{s}\right), 5$ implying that the bridging hydroxo group does not cause a larger electric field gradient around the Fe(III) ions, as compared with the bridging oxo group.

\section{Acknowledgements}

This work was supported by Grants-in-Aid for Scientific Research from the Ministry of Education, Culture, Sports, Science and Technology, Japan, and the Kanazawa University SAKIGAKE Project.

\section{Supporting Information}

A cif format file. This material is available free of charge on the Web at http://www.jsac.or.jp/xraystruct/.

\section{References}

1. B. J. Wallar and J. D. Lipscomb, Chem. Rev., 1996, 96, 2625.

2. L. Que Jr. and W. B. Tolman, Angew. Chem., Int. Ed., 2002 41,1114
3. E. Y. Tshuva and S. J. Lippard, Chem. Rev., 2004, 104, 987.

4. A. J. Jasniewski and L. Que Jr., Chem. Rev., 2018, 118, 2554.

5. X. Zhang, H. Furutachi, S. Fujinami, S. Nagatomo, Y. Maeda, Y. Watanabe, T. Kitagawa, and M. Suzuki, J. Am. Chem. Soc., 2005, 127, 826.

6. G. M. Sheldrick, SHELXS-97, Program for the Solution of Crystal Structures, 1997, University of Göttingen, Germany.

7. G. M. Sheldrick, Acta Crystallogr., 2008, A64, 112.

8. C. Kabuto, S. Akine, T. Nemoto, and E. Kwon, J. Crystallogr. Soc. Jpn., 2009, 51, 218.

9. S. Tanase, M. van Son, G. A. van Albada, R. de Gelder, E. Baouwman, and J. Reedijk, Polyhedron, 2006, 25, 2967.

10. P. C. A. Bruijnincx, I. L. C. Buurmans, Y. Huang, G. Juhász, M. Viciano-Chumillas, M. Quesada, J. Reedik, M. Lutz, A. L. Spek, E. Münck, E. L. Bominaar, and R. J. M. K. Gebbink, Inorg. Chem., 2011, 50, 9243.

11. C. C. Ou, R. A. Lalancette, J. A. Potenza, and H. J. Schugar, J. Am. Chem. Soc., 1978, 100, 2053.

12. M. Sekino, H. Furutachi, K. Tasaki, T. Ishikawa, S. Mori, S. Fujinami, S. Akine, Y. Sakata, T. Nomura, T. Ogura, T. Kitagawa, and M. Suzuki, Dalton Trans., 2016, 45, 469.

13. L. Borer, L. Thalken, C. Ceccarelli, M. Glick, J. H. Zhang, and W. M. Reiff, Inorg. Chem., 1983, 22, 1719.

14. M. K. Coggins, S. Toledo, and J. A. Kovacs, Inorg. Chem., 2013, 52, 13325 . 